\title{
Management of Sensorineural Deafness in Temporal Bone Trauma: A Report of 23 Cases
}

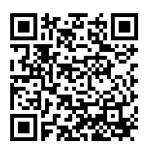

\author{
O Oulghoul*, L Labani, M Chehbouni, O Benhoummad, Y Rochdi and A Raji \\ Ent-Hns Department, Mohammed Vi University Hospital, Morocco
}

Submission: November 11, 2020; Published: January 11, 2021

*Corresponding author: O Oulghoul, Ent-Hns Department, Mohammed Vi University Hospital, Marrakech, Morocco

\begin{abstract}
Introduction: Temporal bone fractures often lead to loss of audio-vestibular function. Otic capsule violating fractures are associated with higher incidence of Sensorineural hearing loss than otic capsule sparing fractures.

Material and methods: Prospective study conducted at the Mohammed VI University Hospital center of Marrakech, from January 2013 to June 2017, covering 23 cases of sensorineural hearing loss in the context of Temporal bone trauma.

Results: The mean age was 31 years (4-56 years), with a clear male predominance (sex ratio 21/2). Clinical symptomatology was characterized by hearing loss in all our patients, otorrhagia in 20 cases, vertigo in 13 cases, facial paralysis in 10 cases, and otoliquorrhea in 5 cases. $96 \%$ of patients presented with labyrinthine fractures. Two cases of pneumolabyrinth and one case of bilateral temporal bone fracture were noted. The audiometry showed sensorineural hearing loss in 9 cases and mixed in 14 cases. In one case the hearing loss was bilateral with severe sensorineural hearing loss on one side and moderate on the other side.
\end{abstract}

Conclusion: Temporal bone fracture is one of the most common traumatic injuries that can cause loss of auditory and vestibular function. The diagnosis must be made within a few hours after the trauma, as the auditory prognosis depends on the earliness of the management. Auditory sequelae can go as far as complete hearing loss, on the affected side.

Keywords: Hearing loss; Tonal audiometry; Temporal bone; Otoscopy; Otorrhagia; Ear drum; Cerebrospinal fluid leak; Rhinoliquorrhea; Hemotympan; Facial paralysis; Pneumolabyrinth; Prophylactic antibiotics; Prednisone; Auditory nerves; Brain

\section{Introduction}

Temporal bone fracture occurs in $18-40 \%$ of head trauma $[1,2]$. These fractures are mostly unilateral, with bilateral fractures reported in $9 \%$ to $20 \%$ [3-5]. Road accidents are the most common cause, with falls and gunshot wounds contributing to a lesser extent. These patients frequently present with multiple lesions of varying severity. Although temporal bone fracture may not represent the patient's acute threatening lesion, early involvement of otolaryngologist in initial assessment and management may improve long-term functional results. Temporal bone fractures often lead to loss of audio-vestibular function. Otic capsule violating fractures are associated with higher incidence of sensorineural hearing loss (SNHL) than otic capsule sparing fractures.

A rapid assessment, early diagnosis and early treatment improve the prognosis.

\section{Patients and Methods}

Prospective study conducted at the Mohammed VI University Hospital center of Marrakech, from January 2013 to June 2017, covering 23 cases of sensorineural hearing loss in context of Temporal bone trauma admitted to the emergency. The clinical, paraclinical, therapeutic and evolutionary data of these patients were collected from direct examination and medical files. All patients underwent a repeated clinical examination including otoscopy, facial and vestibular examination (except for patient with neck trauma), temporal bone HRCT scan, tonal audiometry in all cases, and ABR in one case. Patients with conductive hearing loss, ossicular lesions and data insufficiency were excluded.

\section{Results}

The mean age was 31 years ( $4-56$ years), with $17 \%$ of pediatric population (age $<14$ years), and a clear male predominance (sex ratio $21 / 2$ ). The mechanism of injury includes motor vehicle accident (57\%), assault (25\%), fall (18\%) (Figure 1).

\section{Clinical symptomatology was characterized by}

Hearing loss in all our patients. Otorrhagia in $86 \%$ cases, all these cases had a wound of the external auditory canal. After clarification of otorrhagia, clinical examination objectified a 


\section{Global Journal of Otolaryngology}

perforated tympanic membrane in $30 \%$ of cases and $21 \%$ cases of cerebrospinal fluid leak, all these cases had otoliquorrhea and no case of rhinoliquorrhea and hemotympan with intact ear drum in 9 cases (40\%). Vertigo in 56\% cases, clinical examination showed a horizontal nustagmus in 3 cases, there were no cases of post traumatic VPPB.

$17 \%$ of patients presented Tinnitus. Facial paralysis in $43 \%$ cases. $32 \%$ due to transverse fracture, and $11 \%$ due to a longitudinal fracture. Determination of facial paralysis timing was based on the patient's examination at admission, as well as the observations of the first responders in scene. The palsy was immediate in $28 \%$ and delayed in $15 \%$ (Table 1). $96 \%$ of cases presented a labyrinthine fracture (Figure 2,3), (on case of bilateral sever post traumatic sensorineural hearing loss had a normal CT scan in left temporal bone and a transversal right temporal bone fracture). Two cases of pneumolabyrinth: 8\% (Figure 4). One case of bilateral fracture was noted: (Figure 5).

Figure 1: Sexe ratio.
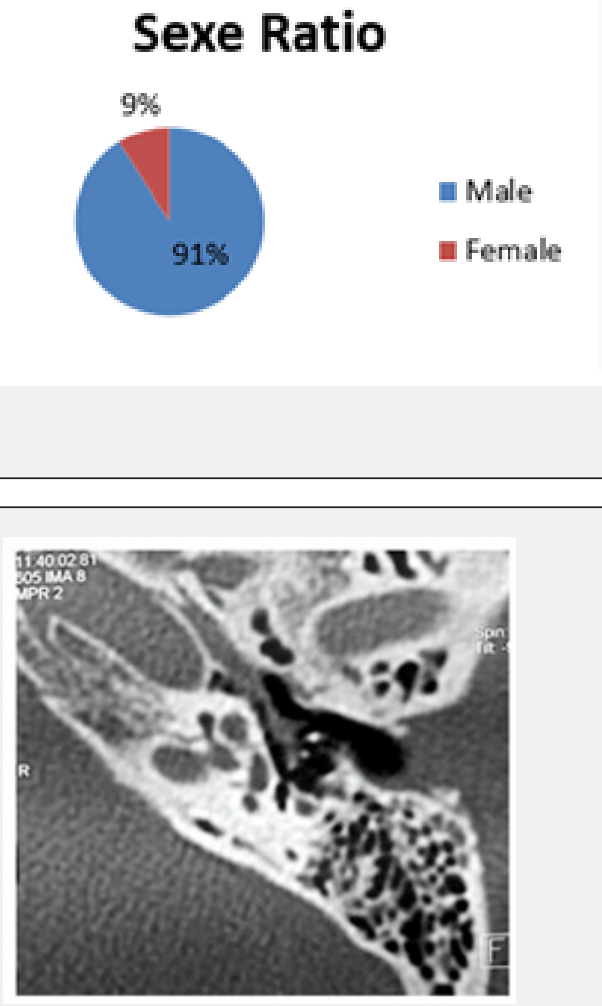

Figure 2: Axial CT-scan of the left temporal bone shows fracture line passing through otic capsule.



Figure 3: Axial CT-scan of the right temporal bone shows fracture line passing through otic capsule. 


\section{Global Journal of Otolaryngology}

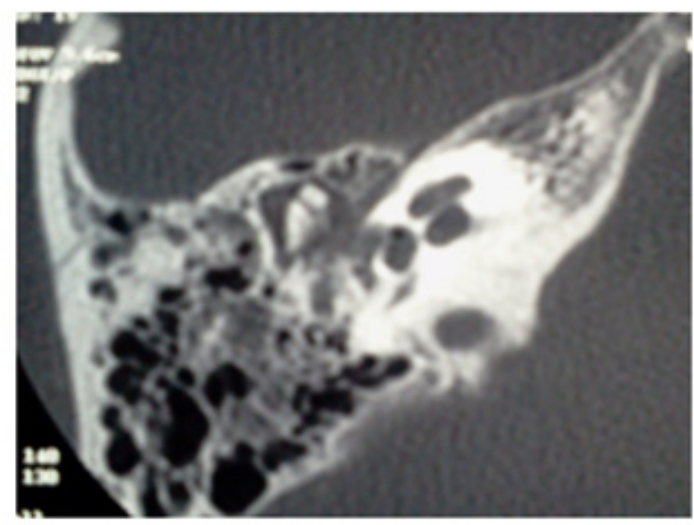

Figure 4: High-resolution CT-scan of the right temporal bone shows air inside the vestibule.

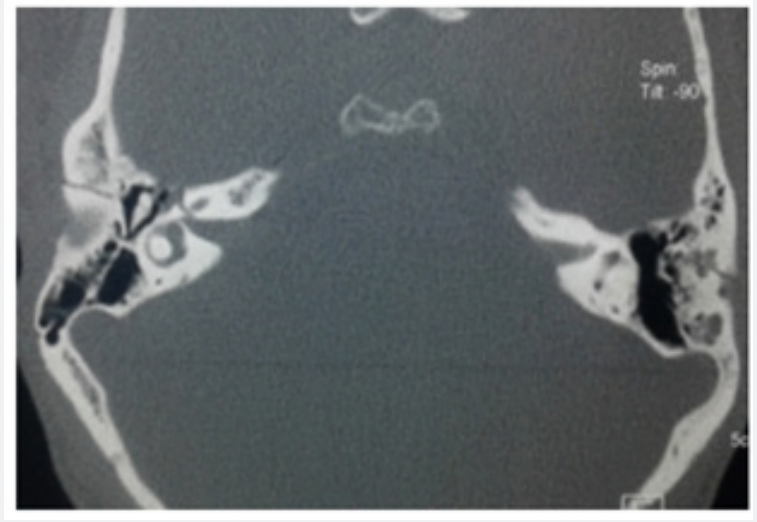

Figure 5: High-resolution axial CT-scan shows bilateral longitudinal fracture of the temporal bone.

Table 1: Clinical manifestation.

\begin{tabular}{|c|c|c|}
\hline Clinical Manifestation & Number of Cases & Percentage\% \\
\hline Hearing loss & 23 & 100 \\
\hline Otorrhagia & 20 & 86 \\
\hline Drum perforation & 7 & 30 \\
\hline CSF leak & 5 & 21 \\
\hline Vertigo & 12 & 56 \\
\hline Tinnitus & 4 & 17 \\
\hline Facial paralysis & 10 & 43 \\
\hline
\end{tabular}

\section{The audiometry showed}

Sensorineural hearing loss in 39\% of cases and mixed in $61 \%$ of cases. The hearing loss was mild in $52 \%$ (between $21 \mathrm{db}$ and $40 \mathrm{db}$ ) of cases, moderate (between $41 \mathrm{db}$ and $70 \mathrm{db}$ ) in $31 \%$, and sever (between $71 \mathrm{db}$ and $90 \mathrm{db}$ ) in $17 \%$ cases. In the one case of bilateral fracture, the hearing loss was severing on one side and moderate on the other side. Treatment was most often conservative by corticosteroids: $1 \mathrm{mg} / \mathrm{kg}$ of prednisone, prophylactic antibiotics. For the patient with bilateral fracture, a bilateral hearing aid has been recommended with strict supervision, a cochlear implant will be the alternative in case of further deterioration of the hearing.

The clinical course after one month of the trauma was marked by the spontaneous improvement of the mixed deafness in 6 cases. The persistence of sensorineural deafness in the other cases with evolution towards total hearing loss in 4 cases. Regression of vertigo (was noted in 9 cases. Persistent tinnitus in two cases. 3 cases have kept moderate instability requiring vestibular reeducation. No patient presented with meningitis during the surveillance.

\section{Discussion}

Temporal bone fracture occurs in $18-40 \%$ of head trauma $[1,2]$. Most of these fractures are unilateral, with bilateral fractures are reported in $9 \%$ to $20 \%$ [3-5]. The primary mechanisms of injury reported include motor vehicle accident (12\%-47\%), assault $(10 \%-37 \%)$, falls $(16 \%-40 \%)$, and gunshot wound 
(3\%-33\%). [1,2,5-9]. Facial nerve injury occurs in $10 \%$ to $25 \%$ of longitudinal fractures and $38 \%$ to $50 \%$ of transverse fractures. Darrouzet and al studied 115 patients who had temporal bone fracture with facial nerve injuries and found paresis in 23\%, complete immediate paralysis in $52 \%$, complete delayed paralysis in $15 \%$, and $10 \%$ whose severe intracranial injuries precluded determination of paralysis onset $[10,11]$.

Reported incidence rates are $14 \%$ to $23 \%$ for sensorineural hearing loss, including 14\% with complete sensorineural hearing loss; and $20 \%$ to $55 \%$ for mixed [3-5,10]. Initial audiometry frequently finds CHL secondary to the hemotympanum; however, it gives an idea on hearing level, especially in SNHL [10]. Full audiological assessment is redone 3 to 6 weeks; the time of resolution of the hemotympanum [10]. Grove reported an incidence of $32.6 \%$ of sensorineural hearing loss. Vertigo after temporal bone trauma may be secondary to either vestibular concussion in otic capsule sparing or vestibular destruction in otic capsule disruption setting. It is usually self-limiting and resolves within 6 to 12 months from central adaptation.

Pneumolabyrinth or pneumocochlea are conditions in which the vestibule or cochlea is filled with air. It is rarely described in the literature [12-13]. For patients with hearing loss, early audiometric evaluation will frequently show conductive hearing loss secondary to hemotympanum. It is therefore advised that audiogram should be repeated about 1-2 months after the injury. Sensorineural hearing loss may show improvement over time but tends to persist and is refractory to treatment Intravenous corticosteroids are sometimes used for sensorineural hearing loss following temporal bone trauma.

Patients who have mild to moderate SNHL are usually treated with standard hearing aid amplification. For unilateral profound SNHL, bone anchored hearing aid has been demonstrated with good outcome [14]. Patients with profound bilateral hearing loss caused by bilateral temporal bone fractures may benefit from cochlear implantation if the functions of the auditory nerves and brain are intact, and scans show cochlear patency. There are several factors to be considered such as the number of surviving ganglion cells, the patency of the cochlea after a fracture labyrinthitis ossificans $[15,16]$.

\section{Conclusion}

Temporal bone fracture is highly associated with loss of auditory and vestibular functions. The consequence is cochleovestibular damage with a clear history and symptomatology. The diagnosis must be made as soon as possible after the trauma as the auditory prognosis can be improved by early treatment. Auditory sequelae can go as far as profound hearing loss.

\section{References}

1. Cannon CR, Jahrsdoerfer RA (1983) Temporal bone fractures. Review of 90 cases. Arch Otolaryngol 109(5): 285-288.

2. Dahiya R, Keller JD, Litofsky NS, P E Bankey, L J Bonassar, et al. (1999) Temporal bone fractures: otic capsule sparingversus otic capsule violating clinical and radiographic considerations. J Trauma 47(6): 1079-1083.

3. Nosan DK, Benecke JE Jr, Murr AH (1997) Current perspective on temporal bone trauma. Otolaryngol Head Neck Surg 117(1): 67-71.

4. Ghorayeb BY, Yeakley JW, Hall JW 3rd, B E Jones (1987) Unusual complications of temporal bone fractures. Arch Otolaryngol Head Neck Surg 113(7): 749-753.

5. Ishman SL, Friedland DR (2004) Temporal bone fractures: traditional classification and clinical relevance. Laryngoscope 114(10): 17341741.

6. Alvi A, Bereliani A (1998) Acute intracranial complications of temporal bone trauma. OtolaryngolHead Neck Surg 119(6): 609-613.

7. Brodie HA, Thompson TC (1997) Management of complications from 820 temporal bone fractures. Am J Otol 18(2): 188-197.

8. Lee D, Honrado C, Har El G, A Goldsmith (1998) Pediatric temporal bone fractures. Laryngoscope 108(6): 816-821.

9. Little SC, Kesser BW (2006) Radiographic classification of temporal bone fractures: clinical predictability using a new system. Arch Otolaryngol Head Neck Surg 132(12): 1300-1304.

10. Darrouzet V, Duclos JY, Liguoro D, Y Truilhe, C De Bonfils, et al. (2001) Management of facial paralysis resulting from temporal bone fractures: our experience in 115 cases. Otolaryngol Head Neck Surg 125(1): 7784.

11. Chang CY, Cass SP (1999) Management of Facial Nerve Injury Due to Temporal Bone Trauma. The American Journal of Otology; 20: 96-114.

12. A F Lipkin, R N Bryan, H A Jenkins (1985) Pneumolabyrinth after temporal bone fracture: documentation by high resolution CT, Am J Neuroradiol 6: 294-295.

13.J L Weissman, H D Curtin (1992) Pneumolabyrinth: a computed tomographic sign of temporal bone fracture. Am J Otolaryngol 13: 113114.

14. Baguley DM, Bird J, Humphriss RL, A T Prevost (2006) The evidence bases for the application of contralateral bone anchored hearing aids in acquired unilateral sensorineural hearing loss in adults. Clin Otolaryngol 31: 6-14.

15. Shin JH, Park S, Baek SH, Sunghee Kim (2008) Cochlear implantation after bilateral transverse temporal bone fractures. Clin Exp Otorhinolaryngol 1: 171-173.

16. Nadol Jr JB, Young YS, Glynn RJ (1989) Survival of spiral ganglion cells in profound sensorineural hearing loss: implications for cochlear implantation. Ann Otol Rhinol Laryngol 98: 411. 
(CC) Commons Attribution 4.0 License

(C) BY DOI: 10.19080/GJO.2021.23.556123

\section{Your next submission with Juniper Publishers} will reach you the below assets

- Quality Editorial service

- Swift Peer Review

- Reprints availability

- E-prints Service

- Manuscript Podcast for convenient understanding

- Global attainment for your research

- Manuscript accessibility in different formats ( Pdf, E-pub, Full Text, Audio)

- Unceasing customer service

Track the below URL for one-step submission https://juniperpublishers.com/online-submission.php 